\title{
PERITONITE BACTERIANA ESPONTÂNEA: impacto das mudanças da microbiologia
}

\author{
Paulo Roberto Lerias de ALMEIDA ${ }^{1}$, Nutianne Schneider CAMARGO², \\ Maximilhano ARENZ ${ }^{2}$, Cristiane Valle TOVO ${ }^{2}$, Bruno GALPERIM ${ }^{2}$ e Paulo BEHAR ${ }^{3}$
}

RESUMO - Racional - A peritonite bacteriana espontânea é uma complicação grave nos pacientes cirróticos com ascite, sendo as alterações das características microbiológicas relatadas nos últimos anos de impacto na escolha do tratamento antibiótico. Objetivo - Avaliar as mudanças na epidemiologia e na resistência antibiótica de bactérias causadoras de peritonite bacteriana espontânea em um período de 7 anos. Métodos - Foram avaliados retrospectivamente todos os casos de pacientes cirróticos com peritonite bacteriana espontânea cuja cultura do líquido de ascite foi positiva, sendo estudados dois períodos: 1997-1998 e 2002-2003. Foram verificados os microorganismos mais freqüentes e a sensibilidade in vitro aos antibióticos. Resultados - No primeiro período (1997-1998) houve 33 casos, sendo 3 (9\%) com infecção polimicrobiana. As bactérias mais freqüentes foram: E. coli em 13 (36,11\%), estafilococos coagulase-negativos em $6(16,66 \%), K$. pneumoniae em 5 (13,88\%), S. aureus em 4 (11,11\%) e S. faecalis em 3 (8,33\%). Em 2002-2003, houve 43 casos, sendo 2 (5\%) com infecção polimicrobiana. As bactérias mais freqüentes foram: estafilococos coagulase-negativos em 16 (35,55\%) S. aureus em 8 (17,77\%), E. coli em $7(15,55 \%)$ e K. pneumoniae em $3(6,66 \%)$. Nenhum paciente realizava profilaxia para peritonite bacteriana espontânea. A prevalência de S. aureus meticilino-resistentes aumentou, no decorrer desse período, de $25 \%$ para $75 \%$, tendo a resistência desse patógeno às quinolonas e a sulfametoxazol-trimetoprim evoluído de $25 \%$ para $50 \%$; somente a vancomicina demonstrou atividade absoluta no decorrer do referido período. Da mesma forma, a prevalência de $E$. coli resistente às cefalosporinas de terceira geração e às quinolonas aumentou de $0 \%$ para 16\%. Conclusão - Houve modificação da população bacteriana causadora de peritonite bacteriana espontânea, com freqüência aumentada de microorganismos gram-positivos, bem como houve aumento da resistência aos antibióticos tradicionalmente utilizados. O estudo sugere a provável iminente inclusão de droga eficaz contra gram-positivos no tratamento empírico da peritonite bacteriana espontânea.

DESCRITORES - Peritonite. Infecções bacterianas. Cirrose hepática. Ascite.

\section{INTRODUÇÃO}

A peritonite bacteriana espontânea (PBE) é definida como a infecção do líquido de ascite em pacientes com cirrose, na ausência de foco abdominal aparente de infecção ${ }^{(8)}$. Provavelmente se origina da passagem de bactérias do lúmen intestinal para a circulação sistêmica e, então, para o líquido de ascite ${ }^{(10)}$. A colonização do mesmo durante episódios de bacteremia é, atualmente, hipótese também aceita para a patogênese da $\mathrm{PBE}^{(4)}$.

Sua prevalência em pacientes cirróticos com ascite, por ocasião da admissão hospitalar, varia entre $10 \% \mathrm{e}$ $30 \%{ }^{(4)}$. Já o risco de desenvolvimento de PBE durante a internação varia de $20 \%$ a $60 \%{ }^{(5)}$, sendo a mortalidade de $20 \%$ a $40 \%$. Falha no tratamento ocorre em $10 \%$, acarretando mau prognóstico, com mortalidade hospitalar de $50 \%$ a $80 \%{ }^{(9)}$. A probabilidade de recurrência de PBE é de $43 \%$ em 6 meses, sendo que a sobrevida em 2 anos após o desenvolvimento da mesma é de apenas $50 \%{ }^{(8)}$.

Em relação ao diagnóstico microbiológico, a cultura do líquido de ascite mostra-se negativa em mais de $60 \%$ dos casos, quando do uso de técnicas convencionais, mesmo na presença de manifestações clínicas sugestivas. O emprego de frascos de hemocultura para inoculação do material coletado possibilita aumento para até $90 \%$ na chance de obter cultura positiva ${ }^{(9)}$.

Mais de 60\% dos episódios de PBE são causados por bactérias gram-negativas entéricas. Os germes mais comuns isolados são Escherichia coli e Klebsiella pneumoniae. Os germes gram-positivos estão presentes em $25 \%$ dos episódios de PBE, sendo as espécies estreptocócicas as mais freqüentemente isoladas ${ }^{(11)}$. Entretanto, durante a última década, considerável mudança na epidemiologia dos germes causadores de PBE tem ocorrido. Essa alteração

${ }^{1}$ Serviço de Medicina Interna; ${ }^{2}$ Serviço de Gastroenterologia; ${ }^{3}$ Comissão de Controle de Infecção Hospitalar, Hospital Nossa Senhora da Conceição, Porto Alegre, RS. Correspondência: Dr. Paulo R. L. de Almeida - Rua Cel. Aurélio Bitencourt, 115 - apt.201-90430-080 - Porto Alegre, Rs. E-mail: pauloalmeida@cpovo.net 
tem sido atribuída ao aumento da sobrevida, ao aumento do número de procedimentos invasivos e ao uso prolongado de antibióticos para descontaminação intestinal ${ }^{(5)}$.

Assim, as alterações das características microbiológicas relatadas nos últimos anos podem ser de impacto na escolha do tratamento empírico.

Os objetivos do presente estudo foram avaliar as mudanças na epidemiologia e nas taxas de resistência bacteriana dos germes causadores de PBE no transcorrer de um período de 7 anos em um hospital geral.

\section{MÉTODOS}

A população avaliada constitui-se de pacientes hospitalizados no Hospital Nossa Senhora da Conceição (HNSC), a maior dentre as quatro unidades hospitalares pertencentes ao complexo denominado Grupo Hospitalar Conceição, Porto Alegre, RS, o qual está vinculado ao Ministério da Saúde e que conta com 1800 leitos. Dentre estes, 830 estão na unidade do presente estudo - HNSC, que apresenta média mensal de internações de 2440 pacientes, sendo $100 \%$ dos serviços voltados para atendimentos aos usuários do Sistema Único de Saúde (SUS). Trata-se, pois, de instituição de referência para casos de maior complexidade, com usuários de baixo nível socioeconômico-cultural.

Foram avaliados, retrospectivamente, todos os casos de pacientes cirróticos com PBE em que a cultura do líquido de ascite foi positiva, sendo estudados dois períodos: $1997-$ 1998 e 2002-2003. Foram verificados os microorganismos mais freqüentes e a sensibilidade in vitro aos antibióticos, assim como a presença ou ausência de quimioprofilaxia. Em ambos os períodos estudados a identificação das amostras bacterianas e o teste de susceptibilidade aos antimicrobianos foram realizados pelo teste automatizado Microscan ${ }^{\circledR}$ (Dade Behring, WalkAway-96).

$\mathrm{O}$ teste qui-quadrado foi utilizado para comparar as proporções entre os microrganismos gram-positivos e gramnegativos nos dois períodos avaliados, através da utilização do Programa Epi-Info ${ }^{(3)}$

\section{RESULTADOS}

No primeiro período (1997-1998) houve 33 casos, sendo 3 $(9,09 \%)$ de infecções polimicrobianas. As bactérias mais freqüentes foram $E$. coli $\mathrm{em} 13$ (36,11\%), estafilococos coagulase-negativos em $6(16,16 \%)$, K. pneumoniae em 5 (13,88\%), S. aureus em 4 $(11,11 \%)$ e $E$. faecalis com 3 casos $(8,33 \%)$.

No segundo período (2002-2003), com 43 casos sendo 2 $(4,65 \%)$ polimicrobianos, os germes mais freqüentes foram estafilococos coagulase-negativos em 16 casos $(35,55 \%)$, S. aureus em 8 casos (17,77\%), E coli em 7 (15,55\%) e K. pneumoniae em $3(6,66 \%)$.

O número total de bacilos gram-negativos foi de 20 $(55,6 \%)$ e de $16(35,6 \%)$ no primeiro e no segundo período do estudo, respectivamente; o número de gram-positivos foi de $16(44,4 \%)$ e $29(64,4 \%)$. A comparação das proporções nos dois períodos, pelo teste do qui-quadrado, mostrou forte tendência de mudança epidemiológica, mas sem diferença estatisticamente significante $(P=0,07)$, tanto em relação à prevalência dos gram-negativos, quanto em relação à dos gram-positivos.

Nenhum paciente fazia uso de profilaxia para PBE.

Outros germes identificados estão descritos na Tabela 1.

TABELA 1. Germes causadores de PBE respectivamente no primeiro período (1997-1998) e segundo período (2002-2003) avaliados

\begin{tabular}{lcccc}
\hline Bactéria & \multicolumn{2}{c}{$1^{\circ}$. Período } & \multicolumn{2}{c}{$2^{\circ}$. Período } \\
& $\mathbf{n}$ & $(\%)$ & $\mathbf{n}$ & $(\%)$ \\
\hline Escherichia coli & 13 & $(36,11)$ & 7 & $(15,55)$ \\
Estafilococos coagulase-negativos & 6 & $(16,66)$ & 16 & $(35,55)$ \\
Klebsiella pneumoniae & 5 & $(13,88)$ & 3 & $(6,66)$ \\
Staphylococcus aureus & 4 & $(11,11)$ & 8 & $(17,77)$ \\
Enterococcus faecalis & 3 & $(8,33)$ & 2 & $(4,44)$ \\
Enterococcus faecium & 1 & $(2,77)$ & 0 & - \\
Enterococcus avium & 1 & $(2,77)$ & 0 & - \\
Streptococcus bovis & 1 & $(2,77)$ & 0 & - \\
Pseudomonas aeruginosa & 1 & $(2,77)$ & 0 & - \\
Salmon/ Arizona & 1 & $(2,77)$ & 0 & - \\
Klebsiella oxytoca & 0 & - & 2 & $(4,44)$ \\
Acinetobacter sp. & 0 & - & 2 & $(4,44)$ \\
Streptococcus viridans & 0 & - & 2 & $(4,44)$ \\
Streptococcus agalactiae & 0 & - & 1 & $(2,22)$ \\
Enterobacter cloacae & 0 & - & 1 & $(2,22)$ \\
Kluyvera ascorbata & 0 & - & 1 & $(2,22)$ \\
Total & $36 *$ & $(100)$ & $46^{* *}$ & $(100)$ \\
\hline
\end{tabular}

$*=33$ casos, 3 polimicrobianos

No que diz respeito às taxas de resistência bacteriana, seu espectro completo nos dois períodos analisados está demonstrado no Quadro 1.

Em relação às taxas de resistência bacteriana, observou-se que a prevalência de $S$. aureus meticilino-resistentes (MRSA) aumentou de $25 \%$ para $75 \%$ entre os dois períodos, o que implica nos mesmos níveis de resistência para com outros antibióticos ß-lactâmicos como cefalosporinas de I e III geração e imipeném. Taxas de resistência algo menores, da ordem de $50 \%$, fez-se presente para com ciprofloxacina e sulfametoxazol-trimetoprim no segundo período, taxas estas duplicadas em relação ao primeiro período. Tão somente a droga vancomicina manteve-se $100 \%$ ativa contra S. aureus e S. epidermidis no decorrer dos períodos analisados.

Já o $E$. faecalis, outro coco gram-positivo com alguma freqüência na PBE, manteve-se $100 \%$ sensível aos antibióticos testados.

No que diz respeito aos germes gram-negativos, um cenário menos sombrio se configura em relação à $E$. coli, cuja resistência antimicrobiana migrou, tão somente, de 0 para $16 \%$ em relação às cefalosporinas de $3^{\mathrm{a}}$ geração e à ciprofloxacina. Não obstante, a K. pneumoniae apresentou taxas de resistência da ordem de $66 \%$ para estes antibióticos no segundo período, três vezes superior àquelas apresentadas no primeiro período, mantendo sensibilidade total apenas ao imipeném. 
QUADRO 1. Taxas de resistência bacteriana na PBE respectivamente no primeiro período (1997-1998) e segundo período (2002-2003) avaliados

\begin{tabular}{|c|c|c|c|c|c|c|c|}
\hline \multicolumn{3}{|c|}{$\begin{array}{l}\text { Germes mais freqüentes } \\
\text { Antibióticos } \\
\end{array}$} & \multirow{2}{*}{$\begin{array}{c}\text { S. aureus } \\
25\end{array}$} & \multirow{2}{*}{$\frac{\text { S. epidermidis }}{33}$} & \multirow{2}{*}{$\frac{\text { E. faecalis }}{-}$} & \multirow{2}{*}{$\begin{array}{c}\text { E. coli } \\
-\end{array}$} & \multirow{2}{*}{$\begin{array}{c}\text { K. pneumonia } \\
-\end{array}$} \\
\hline \multirow{26}{*}{ 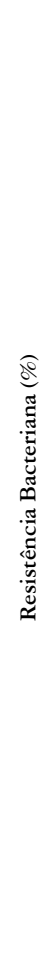 } & $\mathrm{Ox}$ & $1^{\circ}$ & & & & & \\
\hline & & $2^{\circ}$ & 75 & 43 & - & - & - \\
\hline & $\mathrm{Va}$ & $1^{\circ}$ & 0 & 0 & 0 & - & - \\
\hline & & $2^{\circ}$ & 0 & 0 & 0 & - & - \\
\hline & $\mathrm{Im}$ & $1^{\circ}$ & 25 & 33 & 0 & 0 & 0 \\
\hline & & $2^{\circ}$ & 75 & 71 & 0 & 0 & 0 \\
\hline & $\mathrm{Gm}$ & $1^{\circ}$ & 25 & 33 & - & 0 & 60 \\
\hline & & $2^{\circ}$ & 50 & 43 & - & 47 & - \\
\hline & $\mathrm{Am}$ & $1^{\circ}$ & - & - & 0 & 48 & 100 \\
\hline & & $2^{\circ}$ & - & - & 0 & 71 & - \\
\hline & $\mathrm{A} / \mathrm{S}$ & $1^{\circ}$ & - & - & - & - & - \\
\hline & & $2^{\circ}$ & 75 & - & - & 29 & - \\
\hline & $\mathrm{T} / \mathrm{C}$ & $1^{\circ}$ & - & - & - & 8 & 40 \\
\hline & & $2^{\circ}$ & - & - & - & 0 & 66 \\
\hline & Cf & $1^{\circ}$ & 25 & - & - & 38 & 60 \\
\hline & & $2^{\circ}$ & 75 & - & - & 57 & 66 \\
\hline & $\mathrm{Cft}$ & $1^{\circ}$ & 25 & - & - & 0 & 0 \\
\hline & & $2^{\circ}$ & 75 & - & - & 14 & 66 \\
\hline & Cax & $1^{\circ}$ & - & - & - & 8 & 20 \\
\hline & & $2^{\circ}$ & 75 & - & - & 14 & 66 \\
\hline & $C_{p}$ & $1^{\circ}$ & 25 & - & 67 & 0 & 20 \\
\hline & & $2^{\circ}$ & 50 & - & 0 & 14 & 66 \\
\hline & $\mathrm{S} / \mathrm{T}$ & $1^{\circ}$ & 25 & - & - & 33 & 40 \\
\hline & & $2^{\circ}$ & 50 & - & - & 43 & 66 \\
\hline & $\mathrm{A} / \mathrm{C}$ & $1^{\circ}$ & 25 & - & 0 & - & - \\
\hline & & $2^{\circ}$ & 50 & - & 0 & - & - \\
\hline
\end{tabular}

Ox:oxacilina; Va:vancomicina; Im:imipeném; Gm:gentamicina; Am:ampicilina; A/S:ampicilina-sulbactam; T/C:ticarcilina-clavulanato; Cf:cefalotina; Cff:cefotaxima; Cax:ceftriaxona; Cp:ciprofloxacina; S/T:sulfametoxazol-trimetoprim; A/C:amoxicilina-clavulanato.

\section{DISCUSSÃO}

Infecções bacterianas são problemas clínicos importantes em pacientes com cirrose descompensada. Podem estar presentes na admissão ou desenvolver-se durante a hospitalização em $20 \%$ a $60 \%$ dos pacientes ${ }^{(5)}$. Ao mesmo tempo, são causas comuns de morte.

Durante a última década, a prática na hepatologia mudou consideravelmente e isto pode ter influenciado na epidemiologia das infecções bacterianas em hepatopatas. O tratamento de pacientes cirróticos com complicações graves em unidades de terapia intensiva difundiu-se, particularmente com a ampliação dos programas de transplante hepático e procedimentos invasivos usados neste cenário ${ }^{(4)}$. Da mesma forma, novos tratamentos invasivos foram desenvolvidos e são amplamente usados para complicações específicas da cirrose, incluindo ligadura elástica de varizes esofágicas, TIPS e embolização arterial ou ablação percutânea do carcinoma hepatocelular. Esses procedimentos podem, também, estar associados com infecções ${ }^{(12)}$.

Finalmente, a descontaminação intestinal seletiva (DIS) com norfloxacina, que foi introduzida em 1987, é agora largamente usada na profilaxia primária e secundária de PBE, bem como na prevenção da bacteremia espontânea em cirróticos. A DIS contínua é conduta estabelecida (nível de evidência 1) em pacientes que já apresentaram $\mathrm{PBE}$, em pacientes hospitalizados que apresentem menos de $1 \mathrm{~g} / \mathrm{dL}$ de proteína no líquido de ascite e deve ser utilizada também, por período de 7 dias, em pacientes com sangramento do trato gastrointestinal ${ }^{(5,11)}$. Assim, a profilaxia da PBE está centrada na chamada DIS através do uso de quimioterápicos que diminuem seletivamente a proporção de bacilos gram-negativos aeróbicos da flora intestinal, pois esses germes seriam os maiores responsáveis pelas infecções em cirróticos. As drogas usadas são norfloxacina, ciprofloxacina e sulfametoxazol-trimetoprim.

Todos esses fatores podem ter influenciado na mudança etiológica e na resistência antimicrobiana dos germes causadores de PBE em cirróticos ${ }^{(4,5,9)}$. Essa mudança no perfil dos pacientes e dos patógenos deve ser cuidadosamente acompanhada, pois tem implicância direta na escolha empírica dos antimicrobianos.

Assim, outro problema emergente de relevância tem sido as infecções causadas por bacilos gram-negativos resistentes às quinolonas $^{(12)}$. Estudo recente ${ }^{(5)}$ demonstrou que $26 \%$ de todos os episódios de PBE foram causados por bacilos gram-negativos resistentes às quinolonas, com taxas variáveis na dependência do uso prévio de quimioprofilaxia com norfloxacina: $50 \%$ entre aqueles que a praticavam, contra $16 \%$ em relação àqueles que não faziam uso desta estratégia. Também a quimioprofilaxia prolongada com norfloxacina esteve igualmente associada com altas taxas $(44 \%)$ de PBE causadas por gram-negativos resistentes à sulfametoxazol-trimetoprim, sugerindo que este 
antibiótico não seja uma alternativa à norfloxacina ${ }^{(5)}$. Neste mesmo estudo, afortunadamente as cepas de E. coli resistentes às quinolonas mantiveram-se sensíveis às cefalosporinas de terceira geração $0^{(5)}$.

No presente estudo, observou-se que, no decorrer dos períodos analisados, tanto a ciprofloxacina quanto as cefalosporinas de terceira geração mantiveram boa atividade antimicrobiana sobre alguns gram-negativos, como E. coli, que se mostrou resistente apenas em $14 \%$ da amostra do segundo período. Ressalte-se, porém, que nenhum dos pacientes da amostra vinha em uso profilático de norfloxacina. Todavia, já em relação às amostras de Klebsiella $s p$., gram-negativos prevalentes na PBE também nesta casuística, chama a atenção o desenvolvimento de resistência antimicrobiana da ordem de $66 \%$ para os antibióticos acima citados.

Houve também, na presente análise, forte tendência ao aumento de casos de PBE por cocos gram-positivos, sendo relevantes os estafilococos coagulase-negativos e $S$. aureus, apesar de nenhum dos pacientes ter feito uso de antibióticos profiláticos antes da ocorrência de PBE. De importância mais notória, seu perfil de resistência acusou aumentos de $25 \%$ para $50 \%$ - $75 \%$ para com todas as drogas testadas, incluindo-se as cefalosporinas de terceira geração, à exceção da vancomicina.

Observação também importante é a de que, no primeiro período analisado, $S$. aureus foi a bactéria mais identificada no total das culturas realizadas em toda a Instituição ${ }^{(6)}$, tendo S. epidermidis ocupado o sexto lugar; a taxa de MRSA foi de $61 \%$ e a de $S$. epidermidis meticilino-resistente (MRSE) de $66 \%$. No segundo período estudado, $S$. aureus passou para o segundo lugar e o $S$. epidermidis manteve sua posição, sendo que as taxas de resistência à meticilina foram semelhantes ao período anterior ${ }^{(6)}$. Quando se observam as taxas de prevalência e de resistência desses microrganismos especificamente para PBE, verifica-se exatamente o oposto. Isto sugere a existência de causas particulares para esse cenário clínico específico de PBE, a serem buscadas.

A tendência da participação cada vez maior de cocos grampositivos, principalmente estafilococos, nas infecções bacterianas graves de cirróticos hospitalizados, não apenas sob a forma de PBE mas também e especialmente sob a forma de bacteremias em geral, foi ressaltada em relato recente do Clube Internacional de Ascite $^{(12)}$. Em pacientes que recebiam profilaxia para PBE, essa observação era mais notável e, particularmente interessante, bacteremias foram inteiramente devidas a bactérias gram-positivas ${ }^{(1)}$.
Em outro estudo, $53 \%$ da totalidade de infecções bacterianas em cirróticos hospitalizados foram devidas a cocos gram-positivos $\mathrm{e}$, se a infecção fora caracterizada como nosocomial, esse índice subia para $59 \%{ }^{(1)}$. Pacientes manejados em UTI e aqueles submetidos a procedimentos invasivos apresentaram taxas mais elevadas de infecções por cocos gram-positivos (77\% vs. $48 \%$, $P<0,001$ e $58 \%$ vs. $40 \%, P<0,02$, respectivamente) ${ }^{(5)}$.

Talvez de maior relevância seja a observação do estudo francês de CAMPILLO et al. ${ }^{(2)}$. Dentre 200 pacientes cirróticos hospitalizados com mais de 300 infecções documentadas, 93\% foram caracterizadas como nosocomiais e cerca de $2 / 3$ causadas por patógenos gram-positivos. As taxas de mortalidade foram significativamente superiores naqueles com infecções nosocomiais comparado aos com infecções comunitárias $(P=0,0255)$ e nos com infecções estafilocócicas comparados às infecções por outras bactérias $(P<0,001)$.

A natureza da doença subjacente à infecção nestes pacientes - cirrose descompensada -, condição imunossupressora, associada à gravidade dos pacientes atendidos no hospital do estudo, a maior proporção de pacientes tratados em UTI, ao maior número de procedimentos invasivos e ao eventual tempo prolongado de hospitalização, constituem-se em possíveis fatores de risco para infecções por estafilococos.

A valorização e significância clínica de espécies de estafilococos coagulase-negativos obtidas nos mais diversos materiais biológicos continua aumentando à medida que as estratégias diagnósticas e terapêuticas levam a uma proporção crescente de procedimentos invasivos ${ }^{(7)}$. Pacientes hospitalizados imunocomprometidos constituem a população mais vulnerável a esses tipos de patógenos. Todavia, identificá-los como agentes etiológicos ou flora contaminante segue como forte desafio: presença de quadro clínico infeccioso, cultura positiva e ausência de outro microorganismo identificável devem levar à consideração se esse patógeno é ou não agente etiológico ${ }^{(7)}$.

Portanto, este estudo sugere iminente inclusão de antibiótico eficaz contra gram-positivos, principalmente $S$. aureus, ou seja, um glicopeptídio como vancomicina, no tratamento empírico da PBE, no hospital estudado, em futuro próximo. O momento preciso dessa mudança de padrão de conduta terapêutica deverá ser orientado pela vigilância epidemiológica local. Casos específicos de pacientes que apresentem fatores de risco para infecção por estafilococos, entretanto, podem considerar o uso imediato de um glicopeptídio. 
Almeida PRL, Camargo NS, Arenz M, Tovo CV, Galperim B, Behar P. Spontaneous bacterial peritonitis: impact of microbiological changes. Arq Gastroenterol. 2007;44(1):68-72.

ABSTRACT - Background - Spontaneous bacterial peritonitis is a serious complication in cirrhotic patients, and the changes in the microbiological characteristics reported in the last years are impacting the choice of antibiotic used in the treatment. Aim - To evaluate the change in the epidemiology and antibiotic resistance of the bacteria causing spontaneous bacterial peritonitis in a 7 years period. Methods - All the cases of cirrhotic patients with spontaneous bacterial peritonitis with positive cultural examination were retrospectively studied. Two periods were evaluated: 1997-1998 and 2002-2003. The most frequent infecting organisms and the sensitivity in vitro to antibiotics were registered. Results - In the first period (1997-1998) there were 33 cases, 3 (9\%) with polymicrobial infection. The most common were: E.coli in 13 (36,11\%), Staphylococcus coagulase-negative in $6(16,66 \%)$, K. pneumoniae in $5(13,88 \%)$, S. aureus in $4(11,11 \%)$ and S. faecalis in $3(8,33 \%)$. In 2003-2004, there were 43 cases, 2 (5\%) with polymicrobial infection. The most frequent were: Staphylococus coagulase-negative in $16(35,55 \%)$, S. aureus in $8(17,77 \%)$, E. coli in $7(15,55 \%)$ and $K$. pneumoniae in $3(6,66 \%)$. No one was using antibiotic prophilaxys. The prevalence of S. aureus methicillin-resitant to quinolone and trimethoprim-sulfamethoxazole changed from $25 \%$ to $50 \%$, and vancomicin was the only one with absolute activity during all the period. In the same way, the prevalence of E. coli resistant to third generation cephalosporin and to quinolone changed from $0 \%$ to $16 \%$. Conclusion - There was a modification of the bacterial population causing spontaneous bacterial peritonitis, with high frequency of gram-positive organisms, as well as an increase in the resistance to the traditionally recommended antibiotics. This study suggests a probable imminent inclusion of a drug against gram-positive organisms in the empiric treatment of spontaneous bacterial peritonitis.

HEADINGS - Peritonitis. Bacterial infections. Liver cirrhosis. Ascites.

\section{REFERÊNCIAS}

1. Campillo B, Dupeyron C, Richardet JP, Mangeney N, Leluan G. Epidemiology of severe hospital-acquired infections in patients with liver cirrhosis: effect of long-term administration of norfloxacin. Clin Infec Dis. 1998;26:1066-70.

2. Campillo B, Richardet JP, Kheo T, Dupeyron C. Nosocomial spontaneous bacteria peritonitis and bacteremia in cirrhotic patients: impact of isolate type on prognosis and characteristics of infection. Clin Infec Dis. 2002;351:1-10.

3. Dean AG, Dean JA, Coulombia D. Epi Info ${ }^{\text {tm }}$, Version 6.04. Atlanta: Centers for Disease Control and Prevention; jan 2001

4. Fernández J, Bauer TM, Navasa M, Rodés J. Diagnosis, treatment and prevention of spontaneous bacterial peritonitis. Baillieres Best Pract Res Clin Gastroenterol. 2000;14:975-90.

5. Fernández J, Navasa M, Gómez J, Colmenero J, Vila J, Arroyo V, Rodés J. Bacteria infections in cirrhosis: epidemiological changes with invasive procedures and norfloxacin prophylaxis. Hepatology. 2002;35:140-8.

6. Hospital Nossa Senhora da Conceição. Grupo Hospitalar Conceição. Controle de Infecção Hospitalar. Relatórios de resistência bacteriana aos antibióticos de 1998 2003. Porto Alegre;
7. Kloosi WE, Bannerman TL. Update on clinical significance of coagulase-negative staphylococci. Clin Microbiol Rev. 1994;7:117-40

8. Mowat C, Stanley A. Spontaneous bacterial peritonitis - diagnosis, treatment and prevention. Aliment Pharmacol Ther. 2001;15:1851-9.

9. Rimola A, Garcia-Tsao G, Navasa M, Piddock LJ, Planas R, Bernard B, Inadomi JM. Diagnosis, treatment and prophylaxis of spontaneous bacterial peritonitis: a consensus document. J Hepatol. 2000;32:142-53.

10. Sort P, Navasa M, Arroyo V, Aldeguer X, Planas R, Ruiz-del-Arbol L, Castells L, Vargas V, Soriano G, Guevara M, Ginès P, Rodés J. Effect of Intravenous albumin on renal impairment and mortality in patients with cirrhosis and spontaneous bacterial peritonitis. N Engl J Med. 1999;341:403-9.

11. Such J, Runyon B. Spontaneous bacterial peritonitis. Clin Infect Dis. 1998;27:669-76.

12. Wong F, Bernardi M, Balk R, Christman B, Moreau R, Garcia-Tsao G, Patch D, Soriano G, Hoefs J, Navasa M. Sepsis in cirrhosis: report on the $7^{\text {th }}$ Meeting of the Internal Ascites Club. Gut. 2005;54:718-25. 